\title{
La disputa por lo visible y lo recordable
}

\author{
Verónica Capasso \\ capasso.veronica@gmail.com \\ Universidad Nacional de La Plata / CONICET, \\ Argentina
}

Cita sugerida: Capasso, V. (2020). La disputa por lo visible y lo recordable. Aletheia, 11(21), e076.

https://doi.org/10.24215/18533701e076
Resumen: El asesinato de George Floyd en Minneapolis (Estados Unidos) ha desatado múltiples manifestaciones sociales antirracistas en distintos países del mundo, las cuales han adquirido diferentes formatos: marchas, disturbios, pintadas callejeras, militancia hashtag a partir del lema \#BlackLiveMatters y el accionar contra diferentes estatuas de personajes históricos polémicos. Dichos monumentos, conmemoraciones a, principalmente, esclavistas y colonizadores, han sido pintados, mutilados o derribados en señal de protesta, pero también como un modo de disputa por los sentidos y las memorias legitimadas en el espacio público, que, además, tiene como antecedente las manifestaciones en Chile a fines de 2019.

Palabras clave: Manifestaciones sociales, Racismo, Estatuas, Memoria.

\begin{abstract}
Themurderof George Floyd in Minneapolis (UnitedStates) has unleashedmultiple anti-racist social demonstrations in differentcountriesoftheworld. Thesehaveacquireddifferentformats: marches, riots, streetgraffiti, militancyin socialnetworkswiththe hashtag \#BlackLiveMatters and actingagainstdifferentstatuesof controversial historical figures. In thisway, monuments, commemorationsto, mainly, slavers and colonizers, havebeenpainted, mutilated, ordemolished in protest, butalso as a wayto dispute thesenses and thelegitimizedmemories in thepublicspace.
\end{abstract}

Keywords: Social manifestations, Racism, Statues, Memory. 
La situación de crisis, de alcance global, desatada por el coronavirus Covid-19 ha alterado nuestro presente. En el contexto actual, muchos estados "están poniendo en evidencia y amplificando de manera exponencial las consecuencias de un modelo social, cultural y económico que ha guiado las políticas públicas en las últimas décadas: el modelo neoliberal" (Poma y Gravante, 2020, p. 1). Este panorama inauguró y/o potenció un ciclo de protesta que develó aún más claramente las desigualdades sociales (sobre todo las vinculadas al acceso al mundo del trabajo y a un sistema sanitario entendido como derecho) como también potenció la persecución social, camuflada de seguridad pública.

El 25 de mayo de 2020 en la ciudad de Minneapolis (Estados Unidos), la policía local detuvo y mató a George Floyd, un afroamericano de 46 años acusado de querer comprar un paquete de cigarrillos con un billete falso. Su muerte fue causada por asfixia por presión en su cuello: uno de los agentes de seguridad se arrodilló sobre el cuello de Floyd durante más de ocho minutos. Este momento quedó registrado en un video, del cual se desprende la fotografía que dio la vuelta al mundo (imagen 1), viralizada por una multiplicidad de medios y soportes comunicacionales. En ella, el policía mira fijo a la cámara, al espectador u observador, mientras comete el acto brutal. Dicha imagen, que a primera vista podríamos asociar con una función disciplinadora, con una forma de pedagogía que exalta la supremacía del varón blanco (y degrada a ese Otro), logró, gracias a su amplia circulación, indignación y movilización mundial. De esta forma, consideramos que la imagen de una persona negra obtuvo poder cuando antes no lo tenía. Es importante remarcar, sin embargo, que este tipo de hechos de racismo no pueden tomarse como algo circunstancial pues al analizar las historias contemporáneas de diversos países (como Estados Unidos, pero también nuestras sociedades latinoamericanas) encontramos lo que se denomina racismo estructural. "Un racismo estructural o sistémico es uno que se traslada no solo en términos de una discriminación evidente en orden del lenguaje o del comportamiento, sino que se traslada en términos de todas las relaciones en el modo en que se construye el propio tejido social" (De Oto, 2020).

Esta muerte violenta, que, siguiendo a Gayol y Kessler $(2018)^{1}$, podemos considerar un hecho social y político, tuvo diferentes repercusiones generando diversidad de manifestaciones sociales antirracistas, las cuales han adquirido diferentes formatos: marchas, disturbios, pintadas callejeras, militancia hashtag a partir del lema \#BlackLiveMatters y, como ahondaremos a continuación, produjo que se derribaran e intervinieran diferentes monumentos en distintos países del globo. En este sentido, la muerte de Floyd interpeló a un público amplio (no solo negro) que se movilizó colectivamente a la vez que tuvo una amplia cobertura periodística. 


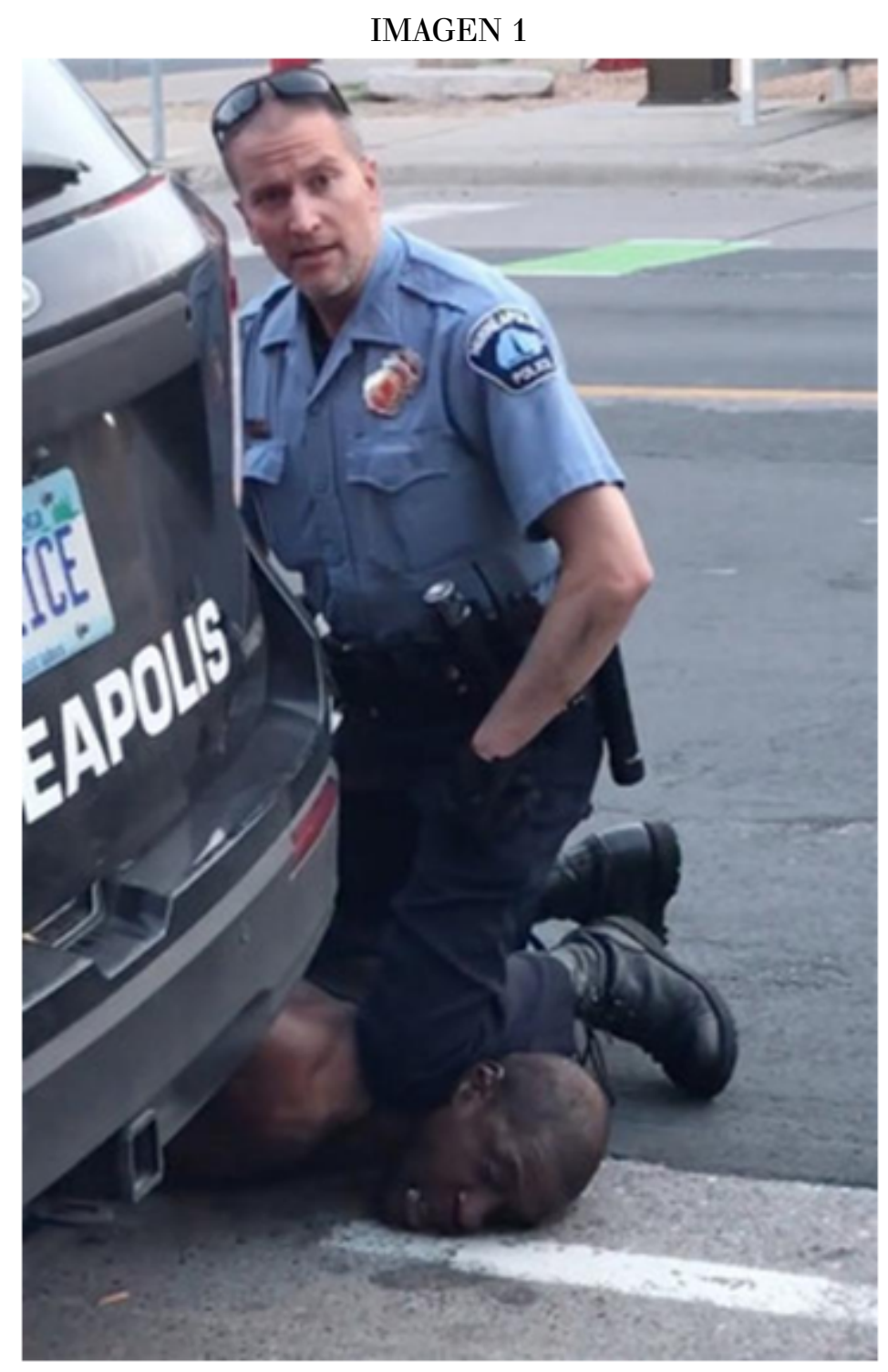

Foto en redes. 2020.

\section{DE IMÁgenEs DE CULTO A HERIDA COLONIAL}

La comprensión del espacio como relacional y performativo es sustancial para comprender las dinámicas de poder que allí operan, su heterogeneidad y la relación entre espacio y sujetos sociales, sin perder de vista las dimensiones histórica, cultural, política y simbólica que lo conforma (Capasso, 2017). Para Massey (2005), el espacio es necesariamente parte integral del proceso de constitución de identidades y también producto del mismo proceso. En este sentido, el lugar nos modifica a partir de practicarlo, de la negociación con otros, de la experiencia compartida o del antagonismo. Las esculturas y monumentos emplazados en el espacio público han estado ligados al homenaje que los Estados hacen a quienes considera sus grandes figuras. Existen distintos objetivos por los cuales se genera este tipo de arte público: homenaje del Estado hacia ciertos personajes o a diversos hechos históricos, la construcción de relatos y memorias sobre la nación y la identidad nacional, entre otros (Capasso, Bugnone, Fernández, 2020). De esta forma, las estatuas en el espacio público se erigen como imágenes de culto, consagradas y veneradas que dan cuenta de cómo se ha tejido una memoria de nación, una historia (cargada de visibilidades e invisibilidades) y un diagrama específico de poder. Los hechos vividos en los últimos meses muestran las tensiones que habitan en estas decisiones. Más aún: las estatuas derribadas por los manifestantes nos permiten tejer un hilo entre la muerte 
injusta de George Floyd (y tantas otras similares) y otras historias de avasallamientos, desprecio, matanza e injusticias acarreadas desde hace siglos, por ejemplo, las derivadas de la conquista y la colonización.

Las estatuas derribadas (imagen 2), decapitadas (imagen 3) o intervenidas en Estados Unidos, Bélgica, Inglaterra o España, son estatuas de traficantes de esclavos, personajes racistas y/o colonizadores: Williams Carter Wickham, Edward Colston, Jefferson Davis, Leopoldo II, Cristóbal Colón, entre otros. Estos monumentos marcan una herida colonial celebrada en el espacio público. Sacarlos (o marcarlos) de ese espacio que los legitima supone una disputa por lo visible y por lo que debe ser (y cómo) recordado y lo que no. En algunos casos, ante esta oleada, fueron los propios gobernantes quienes sacaron las estatuas de sus lugares de privilegio o pidieron tiempo para evaluar el significado histórico de esas acciones.

\section{IMAGEN 2}

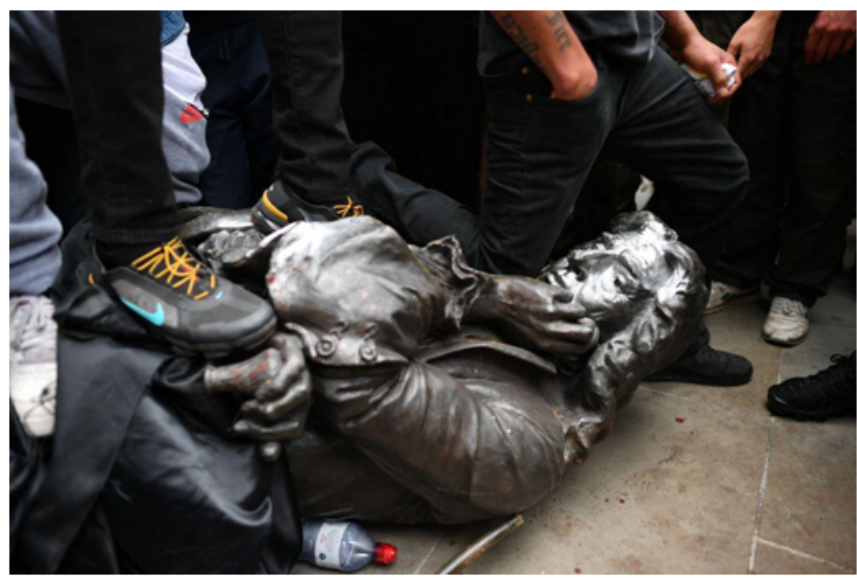

Foto en redes. 2020

IMAGEN 3

Estatua de Cristóbal Colón decapitada en Boston (EEUU). 2020.

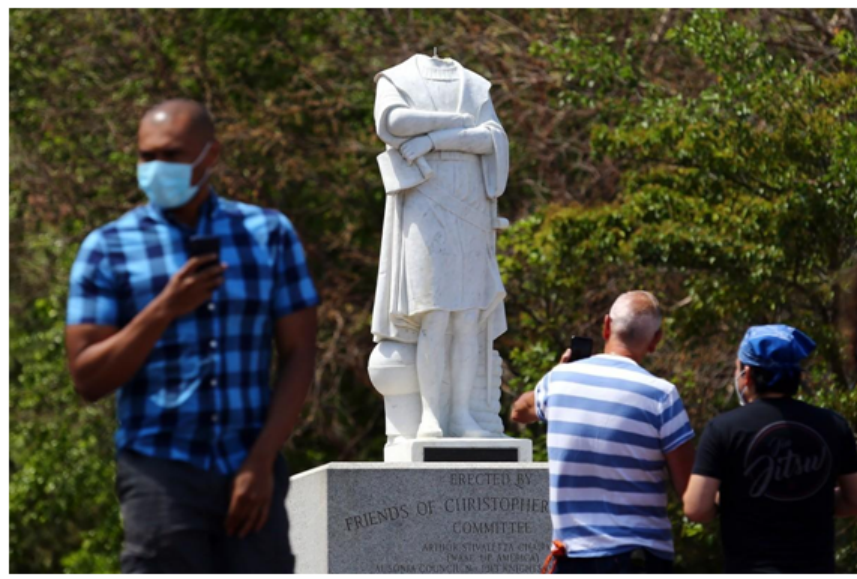

Foto en redes/ AFP

Por otra parte, cabe mencionar en este punto, como antecedente, que ya en las protestas sucedidas en Chile en los últimos meses del año $2019^{2}$, aparecía el cuestionamiento de la historia oficial de diversas estatuas y monumentos (imagen 4). Es decir, si bien la trascendencia de estos hechos tuvo un impacto mediático diferente, tal vez no tan rápidamente amplificado como los sucesos ocurridos luego del asesinato de Floyd, lo cierto es que también la intervención y el derribamiento de esculturas (de la colonización europea y de militares chilenos), fueron el epicentro de reivindicaciones y demandas sociales y políticas. Un ejemplo fue el caso de la estatua del colonizador español Pedro de Valdivia, donde manifestantes mapuches ayudaron a derribarla en la ciudad de Concepción. Así, identificamos el mismo gesto, aunque el origen del acto sea diferente. 


\section{IMAGEN 4}

Estatua de Pedro de Valdivia derribada en la ciudad de Concepción, Chile. 2019.

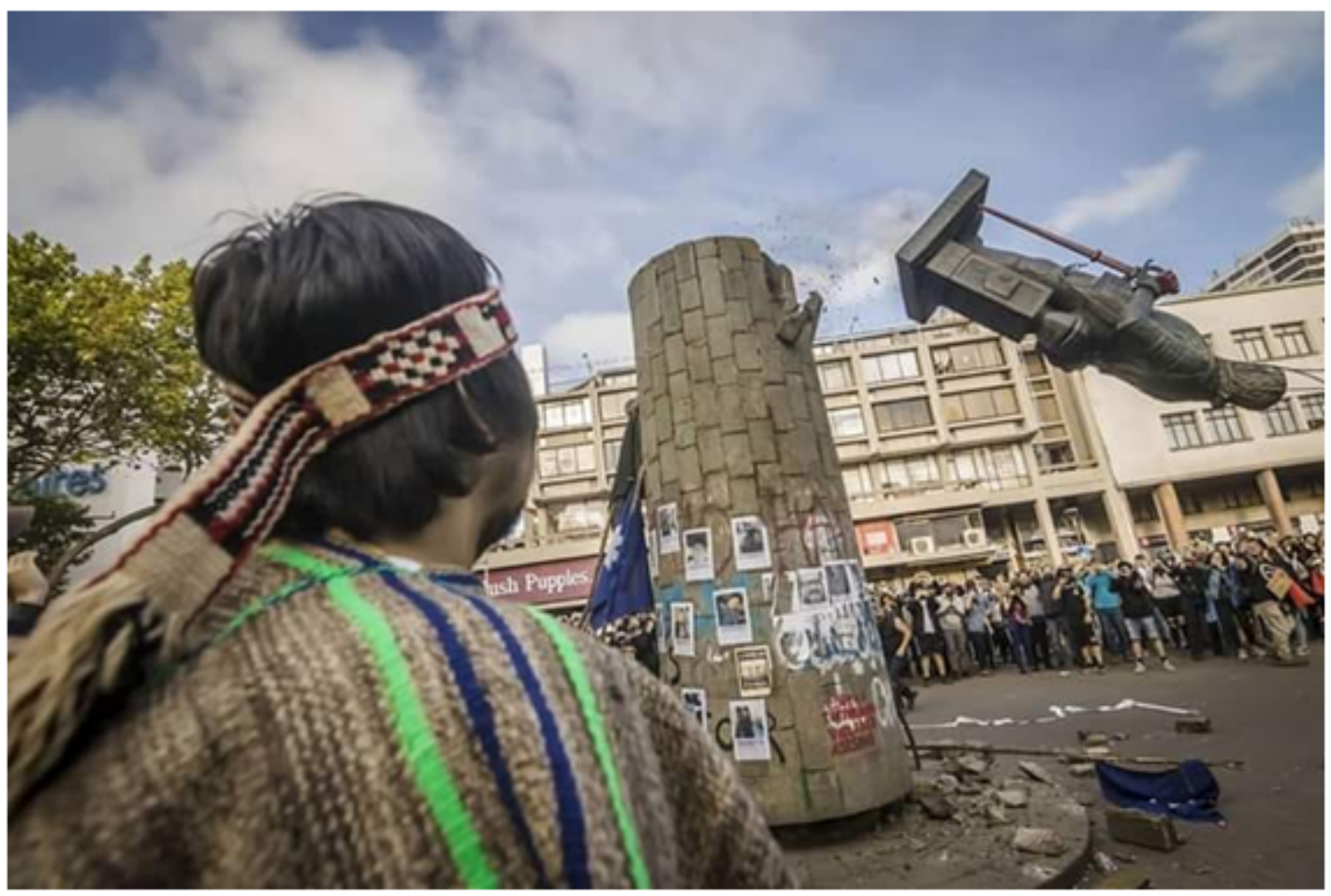

Foto: Esteban Sunyer // Fuente: https://elciudadanoweb.com

También en Chile, al calor de las revueltas de octubre de 2019, surgió el proyecto Monumentos Incómodos, un archivo colaborativo online en la red social Instagram, compuesto de fotografías de monumentos cuestionados. Con la noción de monumentos incómodos, se hace referencia a distintas marcas conmemorativas presentes en el espacio público (como son las estatuas, los nombres de calles, etc.) que hieren a comunidades cuyos derechos fueron y son violentados a través de una visión de la historia que es producto de la colonización, el racismo y la discriminación. El proyecto, entonces, busca visibilizar y debatir sobre este tema y mostrar la resignificación del patrimonio y ya cuenta con una versión en inglés: UncomfortableMonuments.

\section{IMÁGENES AFECTIVAS}

El espacio público es un espacio de disputa. En él convergen y circulan muchas imágenes que nos interpelan, que nos afectan, que son capaces de movilizarnos en tanto, al ser formulaciones temporales y contextuales, pueden disparar articulaciones con otras cosas, con otros temas, con otras historias.

Las acciones emprendidas por los manifestantes, tal como sostiene Traverso "están obligando a analizar con más detalle a las personas que honran estos monumentos, permitiendo así que la historia se vuelva a contar desde el punto de vista de sus víctimas" (2020, s/p). Como bienes simbólicos, sus sentidos y significados son susceptibles de ser puestos en cuestión en cualquier momento. La pregunta incómoda que surge es ¿hay que sacar estos monumentos de la vista de todxs? Y si fuese así, ¿qué implicaría esa decisión? ¿Acaso no podría implicar el olvido no del personaje sino, y más importante, de las acciones que hoy se le cuestionan y que forman parte de nuestra historia? Es importante que tengamos presente que no hablamos de meros ornamentos en el espacio público, sino que son hitos sociopolíticos, que construyen una historia y una memoria social particular. 
Es sugestivo que, en algunos casos, se ha optado por visibilizar las estatuas de otra forma, resignificarlas generando así otros sentidos. Por ejemplo, recientemente, en la Bienal de Sydney (Australia), el artista Nicholas Galanin propuso excavar la sombra proyectada por la estatua del capita\#n James Cook generando así su tumba (imagen 5$)^{3}$. En este caso, no se borró su presencia, sino que se la invoca desde un sentido que impugna al personaje que el monumento colonialista reivindica.

\section{IMAGEN 5}

"Sombra en la tierra, excavación y entierro" Nicholas Galanin

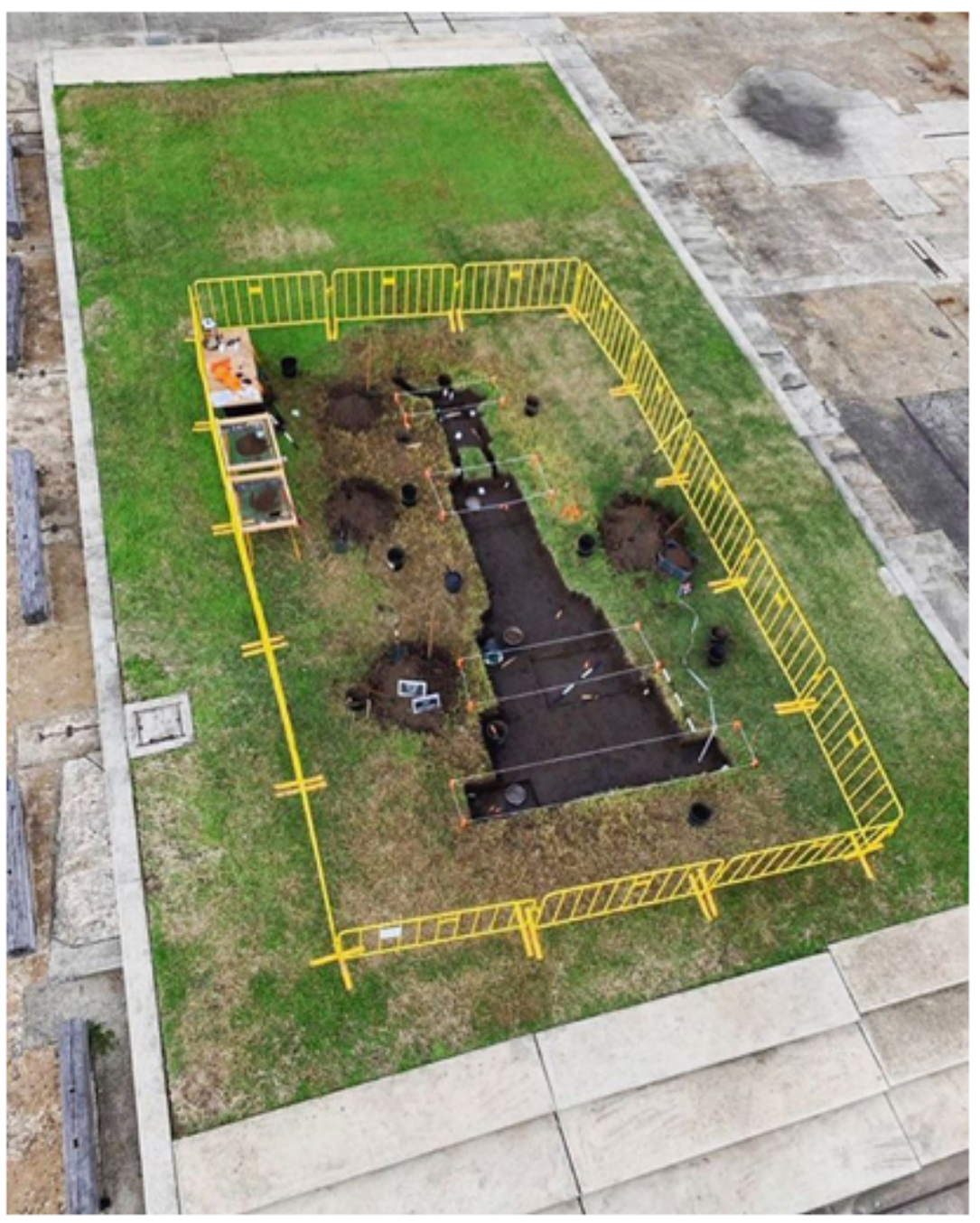

Bienal de Sydney 2020

En suma, los hechos sucedidos en torno a las estatuas y monumentos nos permiten ver cómo estos se han constituido en uno de los lugares donde se canalizó el conflicto. Esto dejó en evidencia que no solo no son signos que representan a lxsciudadanxsmovilizadxs, sino que también manifiestan el odio y el desprecio por, el daño a y la invisibilización de cierta parte de la población.

Las imágenes, entonces, no son meras representaciones. Poseen un papel activo en la interacción con quien observa. Pueden actuar como catalizadoras, pueden, en definitiva, ser la chispa de los conflictos ya existentes. 


\section{REFERENCIAS}

Capasso, V. (2017). Sobre la construcción social del espacio: contribuciones para los estudios sociales del arte. Revista espacio, tiempo y forma. Serie VII. Historia del arte, 5, 473-489. Recuperado de: http://revistas.uned.es/index.p $\mathrm{hp} /$ ETFVII/article/view/17518/16524

Capasso, V.; Fernández, C. y Bugnone, A. (2020). Estudios sociales del arte. Una mirada transdisciplinaria. La Plata: EDULP. Recuperado de: http://sedici.unlp.edu.ar/bitstream/handle/10915/97540/Documento_completo.p df-PDFA.pdf?sequence $=1 \&$ isAllowed $=y$

De Oto, A. (2020). Video 1. Reflexiones Lat Tiempos Pandemia 1 [en línea]. Recuperado de: https://www.youtube.com/watch?v=8jvDJxqjRsU\&fbclid=IwAR13pDo5Y8g9n1Sf7Kk9z-8s-CP9RLhY 211617rUhw5M03jJfq5joIfSB0Y

Gayol, S. y Kessler, G. (2018). Muertes que importan. Una mirada sociobistórica sobre los casos que marcaron la Argentina reciente. Buenos Aires: Siglo XXI Editores.

Jean, Jean, M. (2019). “'Chile despertó'”. Visualidades emergentes en la lucha y resistencia del pueblo movilizado”. En Artefacto visual, 7, 133-140. Recuperado de: https://5551dd67-1da1-4c54-bcb6-7ab3b18e5b71.filesusr.com/u gd/5373fb_9ec80b5b5bac43baaae1a6518af47e8e.pdf

Massey, D. (2005). “La filosofía y la política de la espacialidad, algunas consideraciones” En Arfuch, Leonor. (comp.) Pensar este tiempo. Espacios, afectos, pertenencias. Buenos Aires: Paidos.

Poma, A. y Gravante, T. (2020). Emociones y activismo en tiempos de COVID-19 [en línea]. Recuperado de: https: //movin.laoms.org/2020/04/06/emociones-activismo-covid-19/

Traverso, E. (28 de junio de 2020) "Derribar estatuas no borra la historia, nos hace verla con más claridad". Viento sur. Recuperado de: https://vientosur.info/spip.php?article16111\&fbclid=IwAR2JQvDZVYg_x7h0eBV0_yu LusCkgU--f6jdYmXBO9XWlp2dHvxkwDILUxs

\section{Notas}

1 Tal como analizan agudamente los autores en relación con casos resonantes de la historia reciente en Argentina, algunas muertes violentas sobresalen porque, provocadas por agentes del Estado, pueden generar conmoción social, despertar reacciones sociales, interpelar a los poderes públicos y estar asociadas con cambios particulares (Gayol y Kessler, 2018, p. 7).

2 Al respecto de la situación chilena ver: Jean Jean (2019).

3 Imágenes disponibles en el Facebook de Esfera Pública. 